\title{
Clean and metal-doped bundles of boron-carbide nanotubes: A density functional study
}

\author{
O. Ponomarenko, M. W. Radny, * and P. V. Smith \\ School of Mathematical and Physical Sciences, The University of Newcastle, Callaghan, New South Wales 2308, Australia
}

(Received 19 October 2006; revised manuscript received 22 February 2007; published 16 July 2007)

\begin{abstract}
Carbon nanotubes and many types of inorganic nanotubes can be produced in the form of hexagonal arrays or bundles. In this paper, we discuss results of $a b$ initio density functional theory calculations on the stability, and atomic and electronic structure, of bundles of narrow, clean, and $\mathrm{Li}$ - and $\mathrm{Cu}$-doped, boron-carbide nanotubes related to $\mathrm{LiBC}$ and $\mathrm{CuBC}$ layered compounds. We find that covalent bonding arises between neighboring tubes in the bundles which results in the formation of complex structures. We show that a high concentration of dopant $\mathrm{Li}$ atoms in the bundles can be achieved by a combination of in-tube and interstitial doping. A high concentration of $\mathrm{Li}$ atoms involving only in-tube doping is energetically unfavorable due to repulsive interaction between the $\mathrm{Li}$ atoms. By contrast, increased doping with $\mathrm{Cu}$ atoms can produce a metallic wirelike structure along the longitudinal axis of each tube within the bundle.
\end{abstract}

DOI: 10.1103/PhysRevB.76.035414

PACS number(s): 61.46.-w, 73.22.-f

\section{INTRODUCTION}

With the rapid development of new synthetic routes and methods of characterization, fullerenelike and nanotubular structures related to many exotic inorganic materials have been produced and characterized. ${ }^{1-3}$ These materials include layered transitional metal chalcogenides, ${ }^{4}$ halides (chlorides, bromides, and iodides), nitrides [BN (Ref. 5) and $\mathrm{B}_{x} \mathrm{C}_{y} \mathrm{~N}_{z}$ compounds], metal oxides, hydroxides, and layered ternary and/or quaternary compounds. ${ }^{6}$

A number of nanotubular structures, based on the recently discovered superconductor $\mathrm{MgB}_{2}$ (transition temperature $\left.T_{C} \sim 48 \mathrm{~K}\right),{ }^{7}$ have also been proposed. Research on these types of noncarbon $M \mathrm{~B}_{2}$-type nanotubes (where $M$ is a metal atom) has been stimulated by the prediction that introducing curvature into superconducting layered systems might lead to an increase in $T_{C}{ }^{8}$ Layered $\mathrm{MgB}_{2}$ belongs to the so-called "AlB ${ }_{2}$-type" structure ${ }^{9}$ in which the metal atoms are sandwiched between hexagonal layers of boron atoms. Nanotubes formed from various layered materials of the $\mathrm{AlB}_{2}$ type that have so far been studied include structures based on $\mathrm{MgB}_{2},{ }^{10,11} \mathrm{AlB}_{2},{ }^{9-11}$ silicon diboride, ${ }^{11} \mathrm{BeB}_{2},{ }^{12} \mathrm{ScB}_{2},{ }^{10}$ $\mathrm{TiB}_{2},{ }^{10,13} \mathrm{Ca} / \mathrm{Sr}\left(\mathrm{Al}_{0.5} \mathrm{Si}_{0.5}\right)_{2}$, ${ }^{14}$ and LiBC. ${ }^{10,15,16} \mathrm{LiBC}$ is isoelectronic to $\mathrm{MgB}_{2}$ and it has been shown theoretically that hole doping of layered $\mathrm{LiBC}$ leads to an increase in electronphonon coupling which might result in an increase in $T_{C}{ }^{17}$ Calculations by Mehl et al. ${ }^{18}$ have also shown that the full replacement of the $\mathrm{Mg}$ atoms in $\mathrm{MgB}_{2}$ by $\mathrm{Cu}$, and the partial replacement of boron atoms by carbon, to form a CuBC-like layered compound, might increase its transition temperature to $\sim 50 \mathrm{~K}$.

In a recent paper, ${ }^{16}$ we have reported results of ab initio plane-wave pseudopotential density functional theory (DFT) calculations of infinite, isolated, small-diameter clean, and $\mathrm{Li}$ - and $\mathrm{Cu}$-doped, boron-carbide (BC) nanotubes. Very narrow nanotubes are predicted to possess intriguing physical properties (such as possible enhancement of the electronphonon coupling) due to the effects of electron confinement. ${ }^{19}$ It has also been shown that for some types of noncarbon materials, such as metal chalcogenides, nanotubes of subnanometer diameter can be relatively easily formed. ${ }^{20}$ We have shown that infinite narrow $(6,0)$ and $(4,4)$ clean BC tubes are energetically more stable than the corresponding strips of boron-carbide hexagonal sheets. We have also shown that doping $\mathrm{BC}$ tubes with $\mathrm{Cu}$ atoms results in the formation of covalent bonds between the dopant atoms and the carbon atoms on the tubular shell, while the bonding of $\mathrm{Li}$ with the boron and carbon atoms has a predominantly ionic character. These two effects were shown to dominate the structural and energetic properties of the doped tubes. ${ }^{16}$ Both clean isolated BC tubes and those doped internally with either $\mathrm{Li}$ or $\mathrm{Cu}$ atoms were shown to be metallic.

The aim of the present paper is to extend this earlier work ${ }^{16}$ to discuss the results of $a b$ initio DFT studies on hexagonal lattices (bundles) of both small-diameter clean $(6,0)$ and $(4,4) \mathrm{BC}$ nanotubes and the same tubes doped with either $\mathrm{Li}$ or $\mathrm{Cu}$ atoms. From a theoretical point of view, bundles are interesting because of the possible effects of intertube interactions on the geometric and electronic properties of the structures. Bundle structures may also prove promising in applications. It has been speculated, for example, that a composite based on a two-dimensional nanotubular lattice would become an ideal high- $T_{C}$ superconductor. ${ }^{21}$ It has also been shown that arranging single walled carbon nanotubes (SWCNTs) in bundles, ${ }^{22}$ or doping them with boron, ${ }^{23}$ can significantly improve their lithium storage capacity for usage in ion batteries. In this paper, we study the properties of clean $\mathrm{BC}$ bundles and the effects of doping these bundles with $\mathrm{Li}$ or $\mathrm{Cu}$ atoms at different interior and/or interstitial sites. We have found that lattices of clean and doped BC tubes are more energetically favorable than the corresponding isolated tubes. We have also found that the interactions between $\mathrm{BC}$ tubes arranged within a bundle, and heavily doped by lithium or copper atoms, result in clathratelike structures which are similar to the three-dimensional, layered $\mathrm{LiBC}$ and $\mathrm{CuBC}$ structures. The cavities formed within clean BC bundles have been shown to provide ideal channels for doping to form onedimensional metallic wires. Our results also predict the possibility of achieving much higher concentrations of lithium within a bundle than in the respective isolated tubes.

\section{METHOD AND PROCEDURE}

Infinite hexagonal quasi-two-dimensional lattices (bundles) of BC tubes have been formed by placing selected 


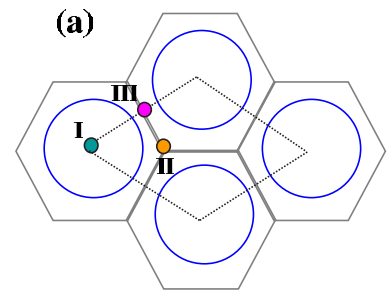

(b)

(c)

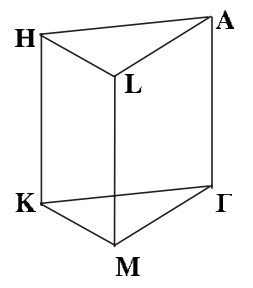

FIG. 1. (Color online) (a) Doping sites for BC tubes arranged in bundles. Site I denotes doping with lithium atoms inside each BC tube, while II and III denote two different interstitial doping sites. (b) The unit cell for the infinite hexagonal BC bundle; $a$ and $c$ denote the lattice constants. (c) Schematic of the irreducible wedge of the first Brillouin zone for a hexagonal bundle showing the main symmetry points.

zigzag and armchair BC nanotubes at the nodes of the "honeycomb" lattice. Inside doping of the zigzag $(6,0)$ and armchair $(4,4)$ BC nanotubes within the bundles was modeled by placing one to three $\mathrm{Li}$ atoms or one to two $\mathrm{Cu}$ atoms per unit cell, respectively, along the longitudinal axis of the tube. Interstitial doping was achieved by placing $\mathrm{Li}$ atoms at the sites II and III shown in Fig. 1.

$A b$ initio DFT spin polarized calculations based on the plane-wave pseudopotential method within the generalized gradient approximation for exchange and correlation (PW91 (Ref. 24)) have been carried out for bundles of clean and doped $(6,0)$ and $(4,4)$ BC nanotubes using the VASP package. ${ }^{25,26}$ We have used the ultrasoft pseudopotentials from the standard VASP set ${ }^{25}$ for the carbon, boron, and copper atoms, and for the Li atoms, we have employed the ultrasoft pseudopotential with $p$-semicore states ${ }^{25,27}$ and an energy cutoff of $286.7 \mathrm{eV}$. Both the nanotube geometries and the positions of the doped metal atoms were fully relaxed during each geometry optimization. These optimizations were carried out with respect to both the atomic coordinates and the size of the hexagonal unit cell, using the conjugate gradient technique. The convergence criterion has been chosen such that all the forces acting on each atom in the bundle were smaller than $10^{-5} \mathrm{eV} / \AA$. For the structural optimizations, we have employed the $3 \times 3 \times 3$ k-point mesh generated using the standard Monkhorst-Pack scheme. ${ }^{28}$ This k-point set has been shown to provide a good representation of both the geometries and energy variations of nanotubular structures. ${ }^{16}$ The electronic structures for the isolated clean and doped $\mathrm{BC}$ tubes were calculated using a mesh of $21 \mathbf{k}$ points along the $\Gamma-A$ direction of the first Brillouin zone. For the corresponding bundles, we have used $81 \mathbf{k}$ points along the $\Gamma-M-K-\Gamma-A-L-H-A$ symmetry directions [see Fig. 1(c)]. The electronic density of states (DOS) plots have been smoothed using a Gaussian function with a width of $0.2 \mathrm{eV}$.

\section{RESULTS AND DISCUSSION}

\section{A. Bundles of clean BC tubes}

\section{Structural and energetic properties of clean BC tubes}

The structural parameters and the total energy per atom for bundles of clean $(6,0)$ and $(4,4) \mathrm{BC}$ tubes are presented in Tables I and II, together with the corresponding data for the isolated tubes. The optimized tubular geometries are shown in Fig. 2, and the charge density plots for bundles formed from $(4,4)$ and $(6,0)$ BC tubes are shown in Figs. 3(a) and 3 (b), respectively. These plots demonstrate a strong localization of the electronic charge between interacting tubes which is characteristic of covalent bonding. Each of the $(4,4)$ tubes in a hexagonal bundle interacts with four neighboring tubes forming carbon-boron and carbon-carbon bonds [Fig. 3(b)]. The length of the $\mathrm{C}-\mathrm{B}$ bond between neighboring $(4,4) \mathrm{BC}$ tubes was found to be $1.64 \AA$, and the length of the $\mathrm{C}-\mathrm{C}$ intertube bond was $\sim 1.53 \AA$. By contrast, each $(6,0) \mathrm{BC}$ tube in a hexagonal bundle forms $\mathrm{C}-\mathrm{C}$ bonds of length $1.65 \AA$ with all of its six neighboring tubes [see Fig. 3(a)]. Due to the formation of these intertube bonds, the values of the total energy per atom for the bundles composed from $(6,0)$ and $(4,4) \mathrm{BC}$ tubes are lower than the corresponding values for the isolated $\mathrm{BC}$ tubes of these symmetries (see Tables II and III and Ref. 16). This suggests that narrow BC tubes are more likely to be synthesized as bundles than isolated tubes.

The intertube interactions that arise due to the packing of $\mathrm{BC}$ tubes into bundles affect the geometric properties of the $\mathrm{BC}$ tubes compared with those of isolated tubes. As we have previously shown, isolated clean $(6,0)$ BC tubes keep a circular tubular cross section. ${ }^{16}$ By contrast, the cross section of these tubes becomes puckered when the tubes are arranged into hexagonal bundles [see Fig. 2(a)]. The cross section of a $(6,0)$ BC tube in a bundle has a symmetrical hexagonal shape, with maximum and minimum dimensions of 5.65 and $5.04 \AA$ compared with 5.01 and $4.97 \AA$, respectively, for the isolated $(6,0) \mathrm{BC}$ tube. As also shown previously, ${ }^{16}$ the optimized isolated $(4,4)$ BC tube has a fairly symmetrical squarelike cross section. In a bundle, it becomes a rather elongated rectangular structure [see Fig. 2(b)], with maximal and minimal dimensions of 6.99 and $3.91 \AA$ compared with 5.94 and $5.89 \AA$, respectively, for an isolated $(4,4)$ BC tube. The lateral cross sections of the bundle formed from $(4,4)$ $\mathrm{BC}$ tubes thus have some similarities with the planar BC layers in three-dimensional $\mathrm{LiBC}$ with the spacing between the BC layers of $3.53 \AA$ (Ref. 17) being quite close to our minimal dimension of $3.91 \AA$ for the deformed $(4,4)$ tubes [see Fig. 3(b)]. As in carbon ${ }^{29,30}$ and silicon ${ }^{31}$ clathrate compounds, patches of $s p^{3}$ bonding resulting from the formation of intertube $\mathrm{C}-\mathrm{C}$ and $\mathrm{C}-\mathrm{B}$ bonds may prove advantageous for intercalation of the lattice cavities with foreign atoms. The mean value for the B-C bond length in the $(4,4)$ and $(6,0)$ tubular shells was found to be longer in bundles of tubes than for the isolated tubes (see Tables I and II).

\section{Electronic properties of clean BC bundles}

The electronic band structures calculated along the $\Gamma-M-K-\Gamma-A-L-H-A$ symmetry directions of the first Brillouin 
TABLE I. Structural data (in $\AA$ ) of isolated $(6,0)$ BC tubes and bundles formed from $(6,0)$ BC tubes. Results are presented for clean tubes and tubes doped both internally and interstitially with lithium.

\begin{tabular}{|c|c|c|c|c|c|c|c|c|c|c|c|c|}
\hline \multirow{2}{*}{$\begin{array}{l}\text { Structure } \\
\text { Type of doping }\end{array}$} & \multirow{2}{*}{$\begin{array}{l}\text { Isolated } \\
\text { clean }(6,0) \\
\text { BC tube }\end{array}$} & \multicolumn{3}{|c|}{$\begin{array}{l}\text { Isolated }(6,0) \mathrm{BC} \text { tube } \\
\text { inside doped with } \mathrm{Li}\end{array}$} & \multirow{2}{*}{$\begin{array}{c}\text { Clean } \\
(6,0) \mathrm{BC} \\
\text { bundle }\end{array}$} & \multicolumn{3}{|c|}{$\begin{array}{l}\text { Bundle of }(6,0) \mathrm{BC} \text { tube } \\
\text { inside doped with } \mathrm{Li}\end{array}$} & \multicolumn{4}{|c|}{$\begin{array}{c}\text { Bundle of }(6,0) \text { BC tube doped } \\
\text { interstitially with } \mathrm{Li}\end{array}$} \\
\hline & & $\begin{array}{l}\text { One Li } \\
\text { inside }\end{array}$ & $\begin{array}{l}\text { Two Li } \\
\text { inside }\end{array}$ & $\begin{array}{l}\text { Three Li } \\
\text { inside }\end{array}$ & & $\begin{array}{l}\text { One Li } \\
\text { inside }\end{array}$ & $\begin{array}{l}\text { Two Li } \\
\text { inside }\end{array}$ & $\begin{array}{l}\text { Three Li } \\
\text { inside }\end{array}$ & $\begin{array}{l}\text { One } \mathrm{Li} \\
\text { at III site }\end{array}$ & $\begin{array}{l}\text { One } \mathrm{Li} \\
\text { at II site }\end{array}$ & $\begin{array}{l}\text { Two } \mathrm{Li} \\
\text { at II site }\end{array}$ & $\begin{array}{l}\text { One } \mathrm{Li} \\
\text { inside }\end{array}$ \\
\hline Mean B-C bond length & 1.54 & 1.55 & 1.55 & 1.56 & 1.57 & 1.58 & 1.57 & 1.58 & 1.56 & 1.57 & 1.58 & 1.58 \\
\hline Shortest B-C bond length & 1.52 & 1.54 & 1.55 & 1.54 & 1.53 & 1.55 & 1.54 & 1.55 & 1.49 & 1.52 & 1.53 & 1.53 \\
\hline Longest $\mathrm{B}-\mathrm{C}$ bond length & 1.55 & 1.55 & 1.56 & 1.58 & 1.63 & 1.62 & 1.61 & 1.67 & 1.64 & 1.62 & 1.63 & 1.64 \\
\hline B-Li distance (min) & & 2.61 & 2.69 & 2.44 & & 2.47 & 2.78 & 2.16 & 3.01 & 2.45 & 2.48 & 2.48 \\
\hline C-Li distance (min) & & 2.63 & 2.52 & 2.43 & & 2.72 & 2.50 & 2.01 & 2.20 & 2.17 & 2.20 & 1.75 \\
\hline Li1-Li2 distance & & & 2.43 & 1.64 & & & & 1.67 & & & & \\
\hline Li2-Li3 distance & & & & 1.62 & & & & 1.63 & & & & \\
\hline $\begin{array}{l}\text { Tubular cross section } \\
(\max )\end{array}$ & 5.01 & 5.02 & 4.97 & 5.00 & 5.65 & 5.57 & 5.52 & 5.75 & 6.12 & 5.60 & 5.63 & 5.66 \\
\hline $\begin{array}{l}\text { Tubular cross section } \\
\text { (min) }\end{array}$ & 4.97 & 4.97 & 4.94 & 4.86 & 5.04 & 4.93 & 4.96 & 4.14 & 3.12 & 4.96 & 4.97 & 5.03 \\
\hline Lattice constant $a$ & 22.92 & 22.92 & 22.92 & 22.92 & 7.30 & 7.25 & 7.25 & 7.61 & 7.70 & 7.28 & 7.36 & 7.40 \\
\hline Lattice constant $c$ & 4.76 & 4.79 & 4.85 & 4.89 & 4.67 & 4.79 & 4.76 & 4.84 & 4.79 & 4.70 & 4.75 & 4.75 \\
\hline $\begin{array}{l}\text { Bond between } \\
\text { neighboring tubes }\end{array}$ & & & & & $\begin{array}{c}\text { Six C-C } \\
\text { bonds } 1.65\end{array}$ & $\begin{array}{c}\text { Six C-C } \\
\text { bonds } 1.68\end{array}$ & $\begin{array}{c}\text { Six C-C } \\
\text { bonds } 1.72\end{array}$ & $\begin{array}{l}\text { Four } \mathrm{C}-\mathrm{C} \\
\text { bonds } 1.62\end{array}$ & $\begin{array}{l}\text { Four } \mathrm{C}-\mathrm{C} \\
\text { bonds } 1.62\end{array}$ & $\begin{array}{c}\text { Six C-C } \\
\text { bonds } 1.68\end{array}$ & $\begin{array}{c}\text { Six C-C } \\
\text { bonds } 1.73\end{array}$ & $\begin{array}{l}\text { Six C-C } \\
\text { bonds } 1.75\end{array}$ \\
\hline
\end{tabular}


TABLE II. Structural data (in $\AA$ ) and difference in total energy (in eV) for isolated tubes and bundles of $(4,4) \mathrm{BC}$ tubes for both clean tubes and tubes doped internally with one or two $\mathrm{Cu}$ atoms.

\begin{tabular}{|c|c|c|c|c|c|c|}
\hline \multirow[t]{2}{*}{ Structure } & \multicolumn{3}{|c|}{ Isolated $(4,4) \mathrm{BC}$ tube } & \multicolumn{3}{|c|}{ Bundle of $(4,4)$ BC tubes } \\
\hline & Clean & $\begin{array}{l}\text { Inside doped } \\
\text { with one } \mathrm{Cu}\end{array}$ & $\begin{array}{l}\text { Inside doped } \\
\text { with two } \mathrm{Cu}\end{array}$ & Clean & $\begin{array}{l}\text { Inside doped } \\
\text { with one } \mathrm{Cu}\end{array}$ & $\begin{array}{l}\text { Inside doped } \\
\text { with two } \mathrm{Cu}\end{array}$ \\
\hline Mean B-C bond length & 1.54 & 1.53 & 1.55 & 1.56 & 1.56 & 1.58 \\
\hline Shortest B-C bond length & 1.51 & 1.46 & 1.50 & 1.49 & 1.48 & 1.54 \\
\hline Longest B-C bond length & 1.55 & 1.62 & 1.61 & 1.64 & 1.68 & 1.68 \\
\hline $\mathrm{B}-\mathrm{Cu}$ distance $(\mathrm{min})$ & & 2.87 & 2.79 & & 2.62 & 2.41 \\
\hline $\mathrm{C}-\mathrm{Cu}$ distance $(\mathrm{min})$ & & 2.20 & 2.36 & & 2.13 & 1.99 \\
\hline $\mathrm{Cu}-\mathrm{Cu}$ distance & & & 2.77 & & & 2.74 \\
\hline $\begin{array}{l}\text { Tubular cross section } \\
(\max )\end{array}$ & 5.94 & 6.18 & 5.98 & 6.99 & 6.19 & 6.96 \\
\hline $\begin{array}{l}\text { Tubular cross section } \\
\text { (min) }\end{array}$ & 5.89 & 4.40 & 4.73 & 3.91 & 4.29 & 3.95 \\
\hline Lattice constant $a$ & & & & 8.20 & 8.15 & 8.15 \\
\hline Lattice constant $c$ & $5.26^{\mathrm{a}}$ & 5.29 & 5.54 & $5.26^{\mathrm{a}}$ & 5.35 & 5.48 \\
\hline $\begin{array}{l}\text { Bonds between } \\
\text { neighboring tubes }\end{array}$ & & & & $\begin{array}{c}\mathrm{C}-\mathrm{C} \text { bonds: } \\
1.53 \\
\mathrm{C}-\mathrm{B} \text { bonds } \\
1.64\end{array}$ & $\begin{array}{c}\mathrm{C}-\mathrm{C} \text { bonds: } \\
1.51 \text { and } 1.52 \\
\mathrm{C}-\mathrm{B} \text { bonds: } \\
1.68\end{array}$ & $\begin{array}{c}\text { C-C bonds: } \\
1.57 \\
\text { C-B bonds: } \\
1.68\end{array}$ \\
\hline $\begin{array}{l}\Delta \text { total energy (isolated } \\
\text { tube-bundle) }(\mathrm{eV})\end{array}$ & & & & 3.04 & 5.89 & 8.06 \\
\hline
\end{tabular}

${ }^{\mathrm{a}}$ For the clean $(4,4) \mathrm{BC}$ tubes (both isolated and in bundles) this number corresponds to double the unit cell length in the longitudinal direction.

zone and the DOS for hexagonal bundles of clean $(6,0)$ and $(4,4)$ BC tubes are presented in Fig. 4. The DOS for the corresponding isolated tubes is also presented for comparison. We observe that, like their isolated counterparts, ${ }^{16}$ the bundles of clean $(4,4)$ and $(6,0)$ BC tubes are metallic.

The differences in helicity and intertube bonding of the bundles of $(6,0)$ and $(4,4)$ tubes are reflected in the character of the $l$-projected DOS for the carbon and boron atoms (not (a)

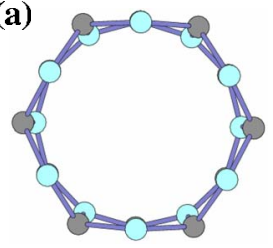

(b)

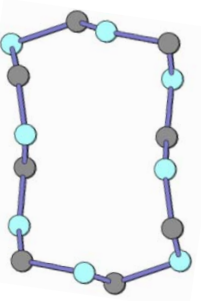

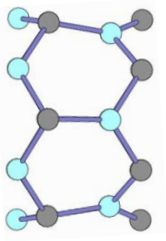

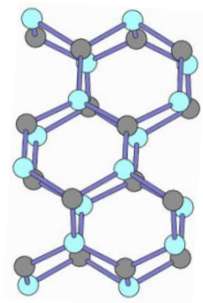

FIG. 2. (Color online) Front and side views of the optimized structures for $(\mathrm{a})(6,0)$ and (b) $(4,4) \mathrm{BC}$ tubes arranged in a hexagonal bundle. shown). For both types of tubes, the valence band DOS close to the Fermi energy is largely populated by the carbon and boron $p$ states. We find that the Boron $p$ states in the conduction band are enhanced for the bundles of $(6,0)$ tubes but are almost suppressed for the bundles of $(4,4) \mathrm{BC}$ tubes. This

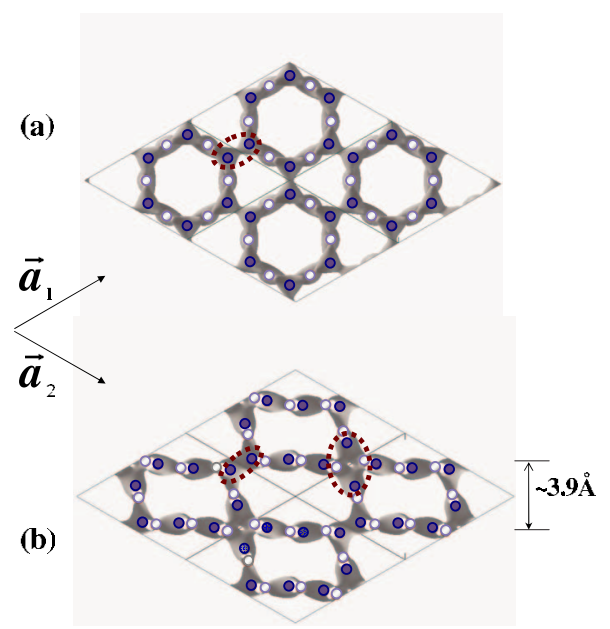

FIG. 3. (Color online) Charge density plots for a bundle of BC tubes. (a) Slice of four neighboring $(6,0) \mathrm{BC}$ tubes in a bundle (top view) showing carbon-carbon intertube bonding. (b) Slice of four neighboring $(4,4) \mathrm{BC}$ tubes in a bundle (top view) showing carbonboron and carbon-carbon intertube bonding. Carbon atoms are denoted by black circles and boron atoms are denoted by white circles. 
TABLE III. Energetics of bundles of $(6,0)$ BC tubes doped internally or interstitially with lithium, compared with isolated $(6,0)$ BC tubes inside doped with lithium atoms.

\begin{tabular}{|c|c|c|c|c|c|c|c|c|c|c|}
\hline \multirow[t]{2}{*}{ Structure } & \multicolumn{3}{|c|}{$\begin{array}{l}\text { Inside-doped isolated } \\
\quad(6,0) \mathrm{BC} \text { tube }\end{array}$} & \multicolumn{3}{|c|}{$\begin{array}{l}\text { Bundle of }(6,0) \text { BC tubes } \\
\text { inside doped with } \mathrm{Li}\end{array}$} & \multicolumn{4}{|c|}{$\begin{array}{c}\text { Bundle of }(6,0) \text { BC tubes interstitially } \\
\text { doped with Li }\end{array}$} \\
\hline & One Li & Two Li & Three Li & $\begin{array}{l}\text { One } \mathrm{Li} \\
\text { inside }\end{array}$ & $\begin{array}{l}\text { Two Li } \\
\text { inside }\end{array}$ & $\begin{array}{l}\text { Three Li } \\
\text { inside }\end{array}$ & $\begin{array}{l}\text { One } \mathrm{Li} \text { at } \\
\text { III site }\end{array}$ & $\begin{array}{l}\text { One } \mathrm{Li} \text { at } \\
\text { II site }\end{array}$ & $\begin{array}{l}\text { Two } \mathrm{Li} \text { at } \\
\text { II site }\end{array}$ & $\begin{array}{l}\text { One Li } \\
\text { inside } \\
\text { and Two Li } \\
\text { at II site }\end{array}$ \\
\hline $\begin{array}{l}\text { Average } \\
\text { binding energy } \\
\text { (eV/atom) }\end{array}$ & 3.79 & 3.21 & 1.60 & 3.02 & 2.27 & 1.12 & 2.92 & 3.54 & 3.40 & 3.34 \\
\hline $\begin{array}{l}\text { Heat of } \\
\text { formation }(\mathrm{eV})\end{array}$ & 3.79 & 2.63 & -1.62 & 3.02 & 1.51 & -1.17 & 2.92 & 3.54 & 3.26 & 3.22 \\
\hline $\begin{array}{l}\text { Intercalation } \\
\text { energy }(\mathrm{eV})\end{array}$ & 4.07 & 6.98 & 5.64 & 3.31 & 5.10 & 4.21 & 3.21 & 3.83 & 7.36 & 10.87 \\
\hline \multirow{2}{*}{\multicolumn{4}{|c|}{$\begin{array}{l}\Delta \text { total energy for the same concentration } \\
\text { of Li atoms in the unit cell }\end{array}$}} & 3.04 & 1.92 & 2.37 & -0.10 & 0.52 & 2.27 & 6.66 \\
\hline & & & & (Iso & ted-bund & $(\mathrm{eV})$ & \multicolumn{4}{|c|}{$\begin{array}{l}\text { (Inside-doped bundle-interstitially } \\
\text { doped bundle) }(\mathrm{eV})\end{array}$} \\
\hline
\end{tabular}

effect can be explained by the fact that in the bundles of $(4,4)$ tubes, both carbon and boron atoms are engaged in the intertube interactions [see Fig. 3(b)]. Due to the charge redistribution resulting from the formation of these intertube bonds, the boron-carbon bonds in the tubular wall of the $(4,4) \mathrm{BC}$ tubes are weakened. This is evidenced by the bond elongation compared with the bond lengths in the isolated $(4,4) \mathrm{BC}$ tube (see Table II). By contrast, only carbon atoms are involved in forming bonds between neighboring tubes in bundles arranged from clean $(6,0)$ BC tubes [see Fig. 3(a)] leading to strong covalent bonds between the $(6,0) \mathrm{BC}$ tubes within a bundle. This effect is also clearly seen in the calculated electronic band structure shown in Fig. 4. While for both the $(6,0)$ and $(4,4)$ bundles the dispersion relations along the $\Gamma-A$ direction retain the $s p^{2}$ character typical of isolated tubes, the dispersion of the bands in other directions is substantially larger for the $(6,0)$ bundles than for the $(4,4)$ bundles indicating different interaction between the tubes within these bundles.

\section{B. Bundles of $(4,4) \mathrm{BC}$ tubes internally doped with $\mathrm{Cu}$ atoms}

\section{Atomic structure}

As we have shown in our previous work on isolated $\mathrm{BC}$ tubes, the effects of doping tubes internally with metal atoms depend on the size of the tubes and their helicity. ${ }^{16}$ Our current calculations have shown that the structure of a hexagonal bundle of $(6,0) \mathrm{BC}$ tubes inside doped with one $\mathrm{Cu}$ atom is changed substantially and becomes very distorted, whereas a bundle of $(4,4)$ BC tubes doped internally with one or two $\mathrm{Cu}$ atoms retains its fairly symmetrical squarelike topology. This indicates the importance of the various structural parameters of the tubes, such as helicity and radius, in forming stable metal-doped bundles.

The optimized structures for a hexagonal bundle of $(4,4)$ $\mathrm{BC}$ tubes inside doped with one and two $\mathrm{Cu}$ atoms are shown in Fig. 5. The structural parameters and the difference in total energy per atom between a bundle and the corresponding isolated $(4,4) \mathrm{BC}$ tubes inside doped with copper atoms are presented in Table II, together with data for clean BC bundles and isolated tubes of $(4,4)$ helicity. Examining Table II, we note that arrangement of the $(4,4)$ tubes into bundles internally doped with one or two $\mathrm{Cu}$ atoms leads to an increase in the bond lengths of the tubular shell compared with the corresponding isolated $(4,4)$ BC tubes. ${ }^{16}$ The length of the unit cell [the lattice vector c in Fig. 1(b)] is also seen to increase with increasing doping concentration.

The shape of the tubular cross section of $(4,4)$ BC tubes in a bundle becomes more squarelike after doping with one $\mathrm{Cu}$ atom compared with the clean $(4,4) \mathrm{BC}$ bundle which has a more elongated cross section [see Figs. 2(b) and 5(a)]. Analysis of the structural data shows that the cross sections of bundles of $(4,4)$ BC tubes doped internally with one $\mathrm{Cu}$ atom and the corresponding isolated $\mathrm{BC}$ tubes inside doped with one $\mathrm{Cu}$ atom, on the other hand, are quite similar (Table II). However, the carbon-boron network on the tubular shell becomes deformed in the $(4,4) \mathrm{BC}$ bundle which is internally doped with one $\mathrm{Cu}$ atom due to interactions with neighboring tubes [see Fig. 5(a)]. Also, each $(4,4)$ BC tube in a bundle which is inside doped with one $\mathrm{Cu}$ atom is bonded to four neighboring tubes through the formation of boron-carbon ( $\sim 1.68 \AA)$ and carbon-carbon $(\sim 1.51 \AA)$ bonds. These bond lengths are quite similar to the corresponding values of 1.64 and $1.53 \AA$ for bundles of clean $(4,4)$ tubes. The bonding structure of the $\mathrm{Cu}$-doped $(4,4) \mathrm{BC}$ tube is illustrated in Fig. 6(a).

Doping with two $\mathrm{Cu}$ atoms restores the hexagonal boroncarbon network on the shells of the tubes in a $(4,4) \mathrm{BC}$ bundle [see Fig. 5(b)]. In this case, the shape and dimensions of the cross sections for bundles of both clean $(4,4)$ BC tubes [see Fig. 2(b)] and those doped with two $\mathrm{Cu}$ atoms are similar (see Table II). Charge density plots for a bundle of $(4,4)$ $\mathrm{BC}$ tubes inside doped with two $\mathrm{Cu}$ atoms are presented in 

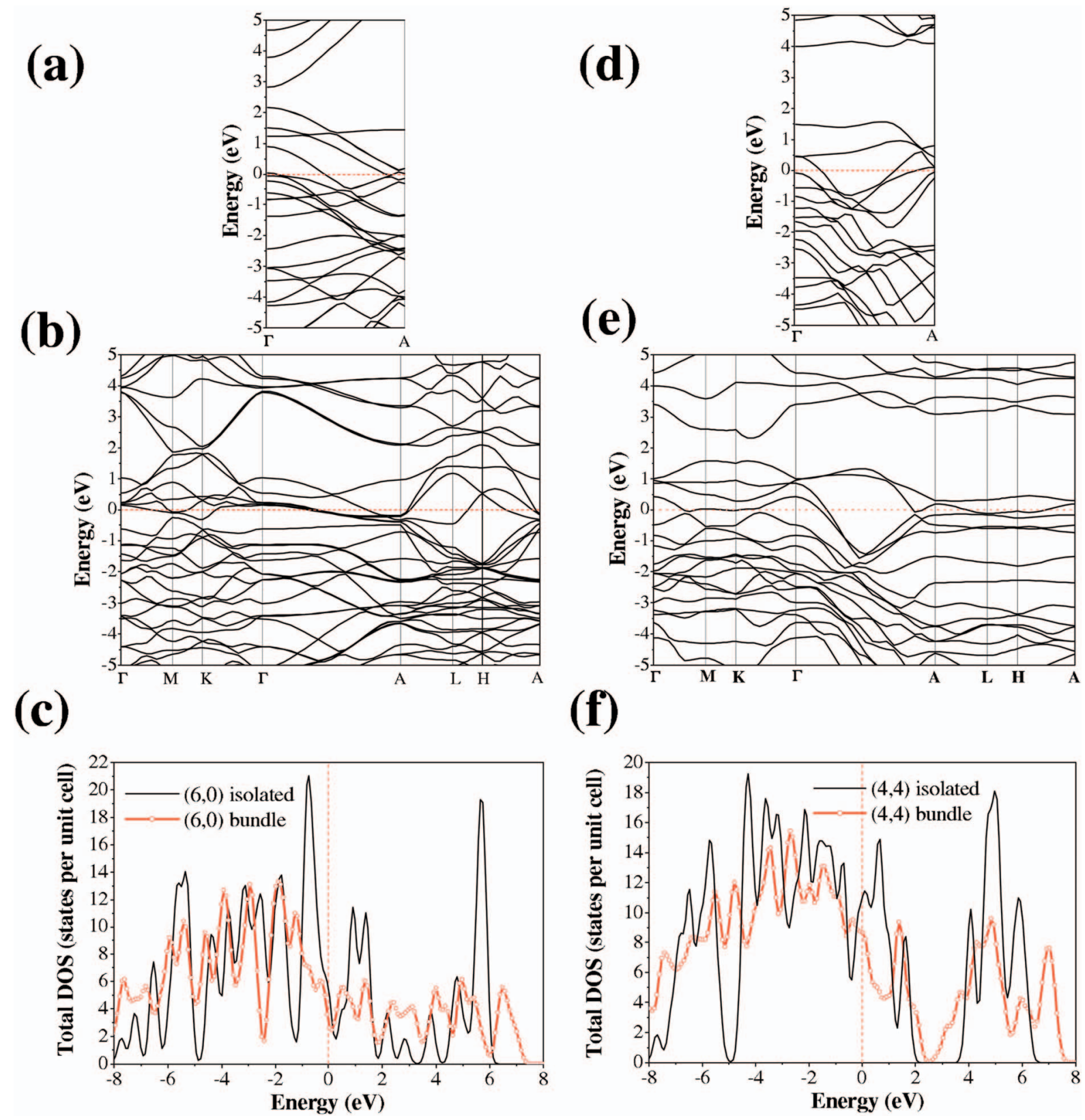

(f)

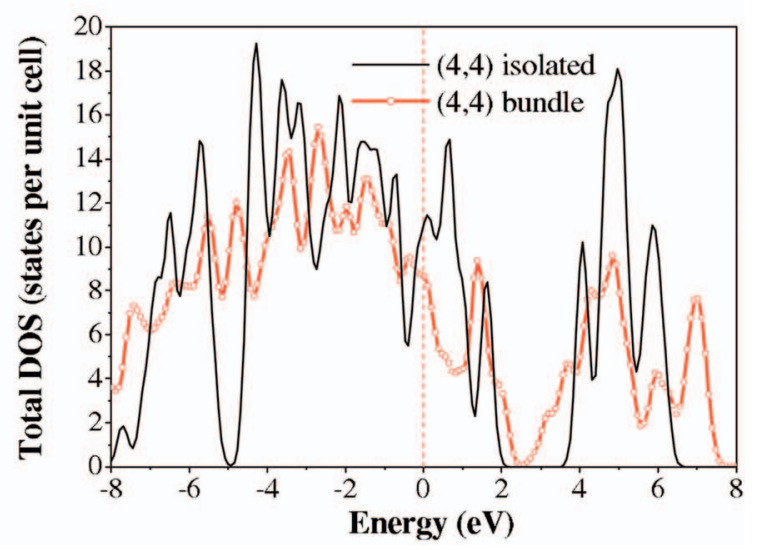

FIG. 4. (Color online) Electronic band structures for (a) isolated $(6,0) \mathrm{BC}$ tubes and (b) bundles of $(6,0) \mathrm{BC}$ tubes, and (c) total DOS for an isolated $(6,0) \mathrm{BC}$ tube and bundles of $(6,0) \mathrm{BC}$ tubes. Electronic band structures for (d) isolated $(4,4) \mathrm{BC}$ tubes and (e) bundles of $(4,4)$ $\mathrm{BC}$ tubes, and (f) total DOS for an isolated $(4,4)$ tube and bundles of $(4,4) \mathrm{BC}$ tubes. The Fermi energy (which is denoted by a dashed line) is set to zero for each structure.

Figs. 6(b) and 6(c) and again show strong covalent bonding between the $\mathrm{BC}$ tubular shells of neighboring unit cells. Similar to the clean $(4,4) \mathrm{BC}$ tubes and those inside doped with one $\mathrm{Cu}$ atom, each tube is bonded to four neighboring tubes via the formation of carbon-carbon (1.57 $\AA$ ) and boron-carbon (1.68 $\AA$ ) bonds.

The charge density distribution for a bundle of $(4,4) \mathrm{BC}$ tubes inside doped with one $\mathrm{Cu}$ atom reveals the formation of four bonds (of length $2.13 \AA$ ) with some covalent character between the internal copper atom and four neighboring carbon atoms on the tubular shell of each $(4,4)$ BC tube [see Fig. 6(a)]. Along the tube, there are no significant interactions between the $\mathrm{Cu}$ atoms. By contrast, in the case for $\mathrm{BC}$ bundles of $(4,4)$ tubes internally doped with two $\mathrm{Cu}$ atoms [see Fig. 6(b)], each copper atom exhibits strong bonding with only two carbon atoms in the tubular shell, with the bond length of $1.99 \AA$. Also, each tube in the bundle exhibits a continuous charge distribution between the $\mathrm{Cu}$ atoms along the longitudinal axis of the tube which can be viewed as a metallic wire piercing through the boron-carbon bundle [see Fig. 6(c)]. This metal wirelike structure may lead to enhanced conductivity in the longitudinal direction of the bundle compared with that of a bundle of $(4,4)$ BC tubes doped with one $\mathrm{Cu}$ atom per unit cell. As can also be seen from Table II, bundles of $(4,4)$ BC tubes doped with one and 
(a)

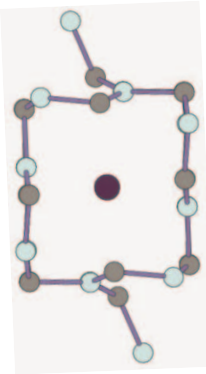

(b)

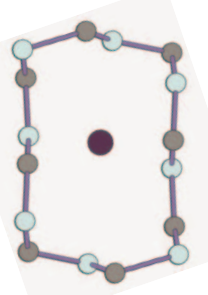

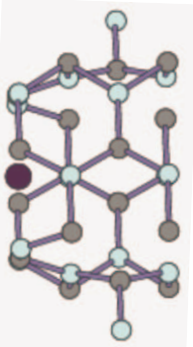

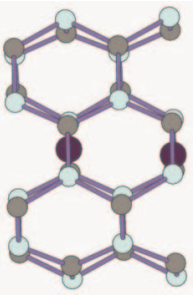

(a)

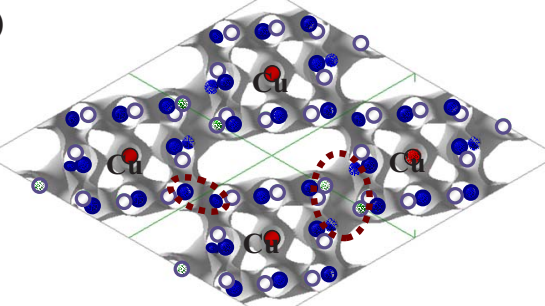

(b)

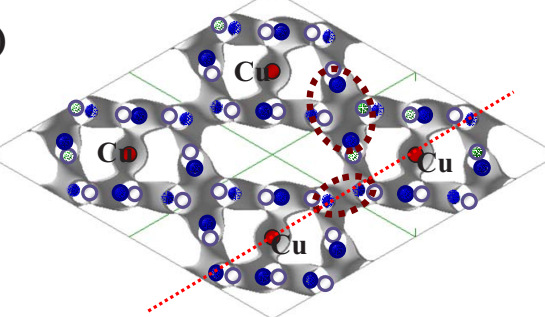

(c)

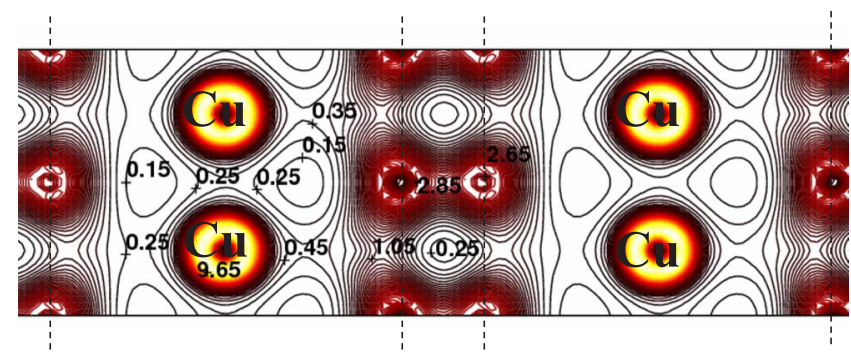

FIG. 6. (Color online) (a) Four unit cells for a bundle of $(4,4)$ $\mathrm{BC}$ tubes doped with one $\mathrm{Cu}$ atom (top view) showing the formation of boron-carbon and carbon-carbon bonds with four neighboring tubes in the bundle. (b) Total charge density plot for a bundle of $(4,4)$ BC tubes doped inside with two $\mathrm{Cu}$ atoms showing the carbon-boron and carbon-carbon intertubular bonding. (c) A contour plot of the electronic charge distribution (in units of $e$ ) on a longitudinal slice for two neighboring tubes showing the interactions between the copper atoms inside each tube and between the carbon atoms on the adjacent tubes.

we have chosen sites to be occupied by dopant atoms which would yield maximum symmetry for the doped bundle. Figure 1(a) presents a schematic of these doping sites. Site II corresponds to a site where a lithium atom interacts equidistantly with three neighboring $(6,0) \mathrm{BC}$ tubes, while at site III, the lithium atom is equidistant from two neighboring tubes. The fully optimized structures of bundles of $(6,0)$ BC tubes doped both inside and at interstitial sites are shown in Figs. 8 and 9, respectively. Structural data and energy values for bundles of $(6,0) \mathrm{BC}$ tubes doped internally and interstitially with one, two, and three $\mathrm{Li}$ atoms are presented in Table I, together with the data for the isolated clean and inside-doped $(6,0) \mathrm{BC}$ tubes.

Internal doping of $(6,0) \mathrm{BC}$ tubes with $\mathrm{Li}$. Inside doping of $(6,0) \mathrm{BC}$ tubes in a bundle with one or two $\mathrm{Li}$ atoms does not lead to noticeable changes in the shape and size of the tubular cross section, or in the boron-carbon bond lengths on the tubular shell, compared to a bundle of clean $(6,0) \mathrm{BC}$ tubes [see Table I and Figs. 2(a), 8(a), and 8(b)]. The tubes inside doped with one and two Li atoms do, however, be- 
(a)

\section{(b)}

(c)
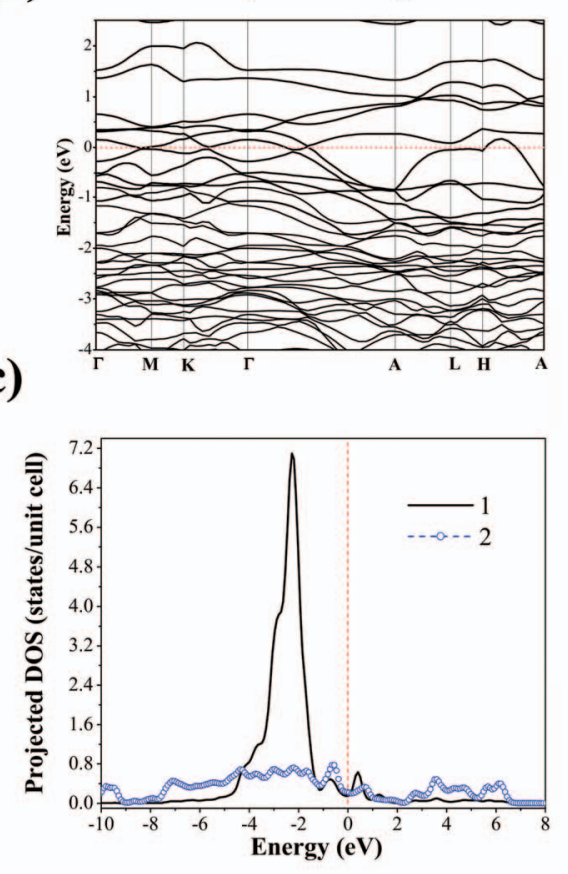

(d)

(e)
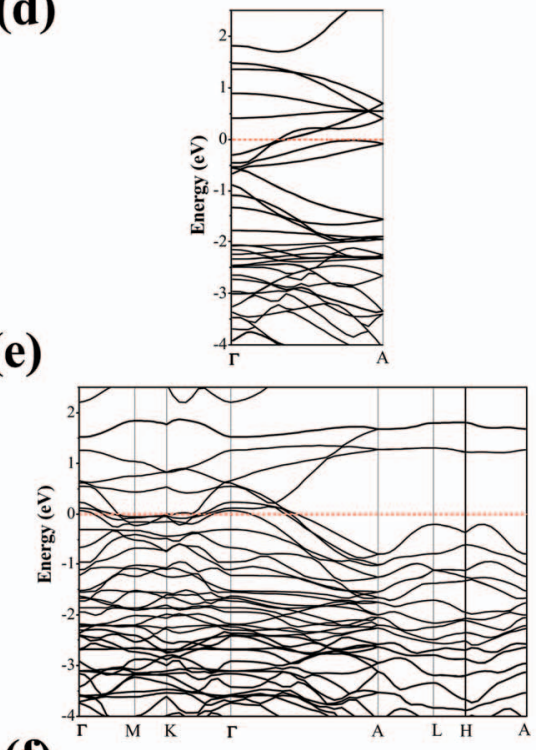

(f)

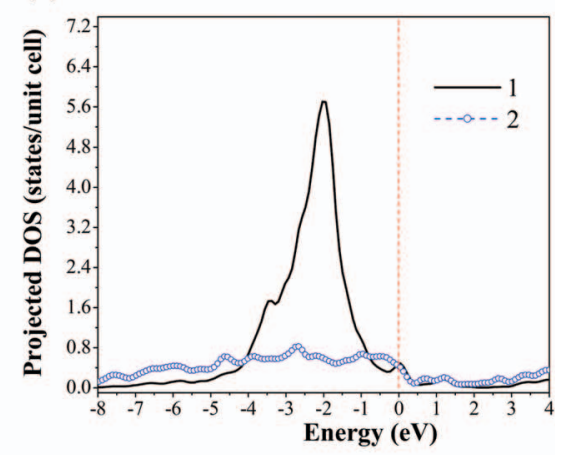

(g)

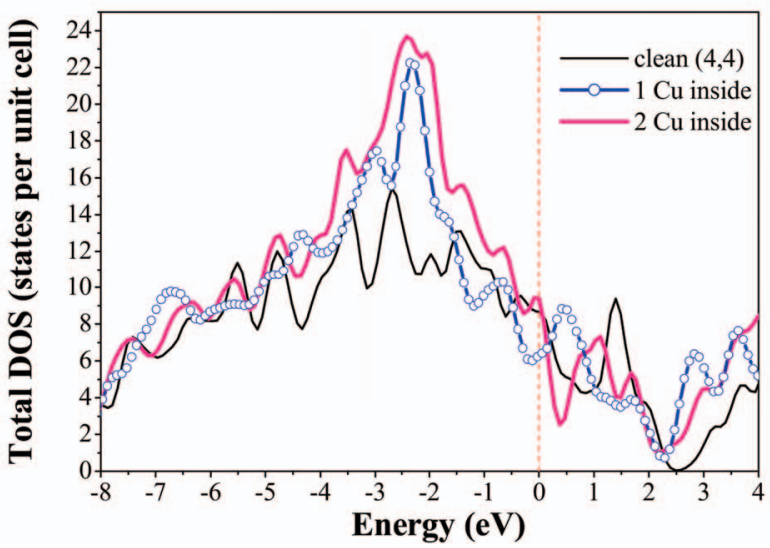

FIG. 7. (Color online) Electronic band structures and projected DOS for bundles of (4,4) BC tubes doped internally with [(a)-(c)] one Cu atom and $[(\mathrm{d})-(\mathrm{f})]$ two $\mathrm{Cu}$ atoms. (g) Total DOS for a bundle of $(4,4) \mathrm{BC}$ tubes undoped and doped internally with one or two $\mathrm{Cu}$ atoms. In (c) and (f), a thick solid curve (1) denotes the $d$ states of $\mathrm{Cu}$ atoms, while an empty circle curve (2) corresponds to the cumulative DOS from $s$ and $p$ states of $\mathrm{C}, \mathrm{B}$, and $\mathrm{Cu}$ atoms.

come more puckered when arranged into bundles, compared with the corresponding isolated tubes. ${ }^{16}$ The tubular cross section is considerably larger for the bundled tubes than for the corresponding isolated $(6,0) \mathrm{BC}$ tubes inside doped with one and two $\mathrm{Li}$ atoms $(5.57 \AA$ versus $5.02 \AA$ and $5.52 \AA$ versus $4.97 \AA$ for the maximum dimension, respectively). Inside doping with three $\mathrm{Li}$ atoms of $(6,0) \mathrm{BC}$ tubes in bundles changes the shape of the tubular cross section from approximately hexagonal to elliptical, as shown in Fig. 8(c). This differs significantly from the symmetric circular cross section of isolated $(6,0)$ tubes inside doped with three $\mathrm{Li}$ atoms. ${ }^{16}$

Analogous to the bundle of clean $(6,0)$ BC tubes [Fig. $3(\mathrm{a})$, each tube in bundles of $(6,0) \mathrm{BC}$ tubes doped internally with one and two Li atoms forms intertubular carboncarbon bonds with six neighboring tubes. However, each 
(a)
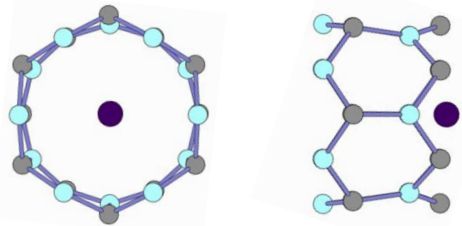

(b)
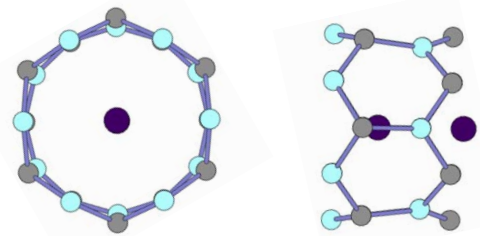

(c)

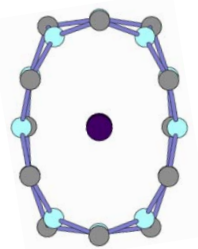

FIG. 8. (Color online) Top and side views of optimized bundles of $(6,0)$ BC tubes doped internally with (a) one $\mathrm{Li}$, (b) two $\mathrm{Li}$, and (c) three $\mathrm{Li}$ atoms.

$(6,0)$ BC tube doped internally with three lithium atoms forms carbon-carbon bonds with only four neighboring tubes in the bundle [see Fig. 10(a)], similar to the behavior exhibited by bundles of clean and $\mathrm{Cu}$-doped $(4,4) \mathrm{BC}$ tubes (Fig. 6). As a consequence, the cross section of this bundle also bears some resemblance to the layered structure of bulk LiBC.

As can be seen from Table I, the length of the carboncarbon intertube bonds is increased from $1.65 \AA$ for the clean $(6,0) \mathrm{BC}$ bundles to $1.68 \AA$ for the $(6,0) \mathrm{BC}$ bundle doped internally with one $\mathrm{Li}$, and to $1.72 \AA$ for the $(6,0) \mathrm{BC}$ bundle inside doped with two $\mathrm{Li}$ atoms. The carbon-carbon

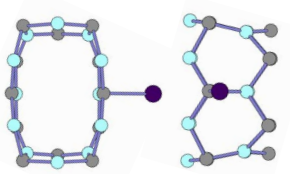

(a)

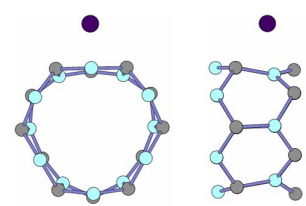

(b)

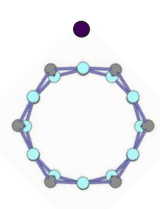

$\bullet \quad(c)$

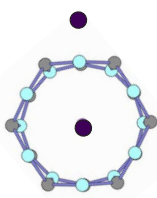

-

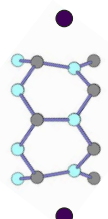

(c)

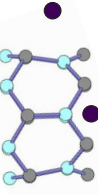

(d)
FIG. 9. (Color online) Front and side views of the interstitial doping of a $(6,0) \mathrm{BC}$ bundle with (a) one Li atom at the III site, (b) one $\mathrm{Li}$ atom at the II site, (c) $\mathrm{Li}$ atoms at both II sites, and (d) $\mathrm{Li}$ atoms at both II sites plus one $\mathrm{Li}$ inside the tube.
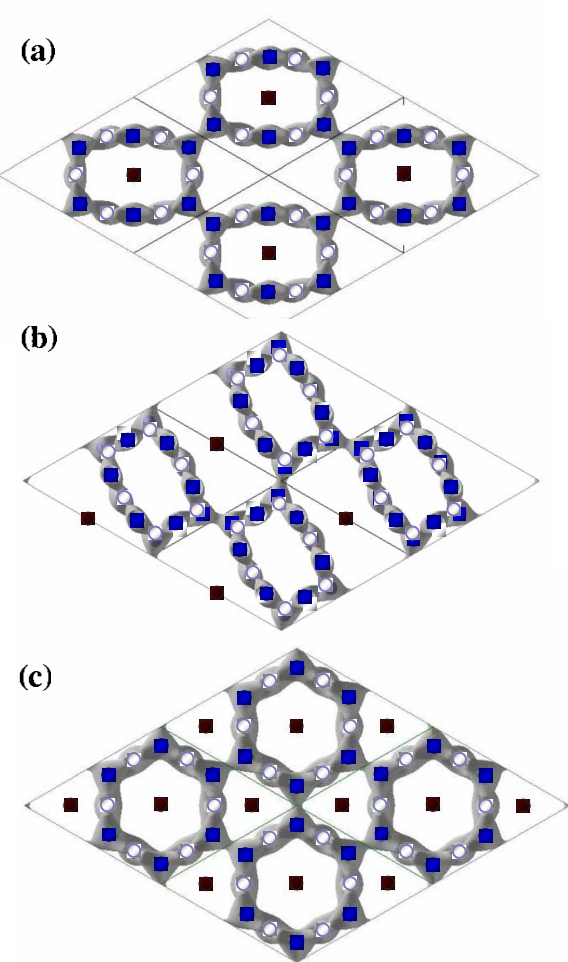

FIG. 10. (Color online) Charge density isosurface plotted for four unit cells of a bundle formed from (a) $(6,0) \mathrm{BC}$ tubes inside doped with three lithium atoms per cell, (b) $(6,0) \mathrm{BC}$ tubes interstitially doped with one $\mathrm{Li}$ atom per unit cell at the III site, and (c) $(6,0) \mathrm{BC}$ tubes doped interstitially with two lithium atoms per unit cell at II sites and one lithium atom inside each tube.

intertubular bonds in a bundle of $(6,0) \mathrm{BC}$ tubes inside doped with three $\mathrm{Li}$ atoms, on the other hand, are somewhat shorter at $1.62 \AA$ than for bundles of either clean $(6,0) \mathrm{BC}$ tubes or those internally doped by one or two Li atoms. All of these structural changes of the tubes with increased doping can be explained by changes in the intertubular bonding due to charge transfer between the $\mathrm{Li}$ atoms inside the tube and the boron-carbon network on the tubular shell. Such charge transfer from dopant $\mathrm{Li}$ atoms to the $\mathrm{BC}$ tubular shell has been previously demonstrated for isolated BC tubes doped with $\mathrm{Li}^{16}{ }^{16}$ To determine the extent of this charge transfer for our Li-doped BC bundles, we calculated the difference in total charge between the Li-doped and clean $\mathrm{BC}$ bundles within a cylindrical volume of radius $0.8 \AA$ (this value is $\sim 30 \%$ larger than the ionic radius of $\mathrm{Li}$ ), centered on the line of $\mathrm{Li}$ dopant atoms and one periodic repeat distance in length. The total charge within this volume was found to be $0.12 e$ and $0.26 e$ for doping with one and two Li atoms, respectively, and 3.0e for doping with three $\mathrm{Li}$ atoms. For all of these cases, there is no significant charge density between the $\mathrm{Li}$ atoms at the center of the tube and the tubular wall. These results establish that the $\mathrm{Li}$ atoms give up virtually all of their charge to the $\mathrm{BC}$ network of the tubular shell for doping with one and two $\mathrm{Li}$ atoms but retain their charge when the doping concentration is increased to three $\mathrm{Li}$ atoms per cell. These results explain the initial increase in the intertubular $\mathrm{C}-\mathrm{C}$ bond length for one and two lithium atoms, 
and the sudden decrease for doping internally with three $\mathrm{Li}$ atoms.

Interstitial doping of $(6,0) B C$ tubes. The dimensions of the tubular cross section, and the mean boron-carbon bond length of the tubular shell, are not significantly changed by interstitial doping at the II site(s). However, the intertubular carbon-carbon bond lengths increase with increasing concentration of $\mathrm{Li}$ atoms, as shown in Table I. The nature of the bonding in bundles of $(6,0)$ BC tubes interstitially doped with Li atoms (Fig. 9) is elucidated by the charge density plots shown in Figs. 10(b) and 10(c). In the $(6,0) \mathrm{BC}$ bundles doped with one or two $\mathrm{Li}$ atoms at the II sites, and in the bundle interstitially doped with two $\mathrm{Li}$ atoms at the II sites plus one $\mathrm{Li}$ atom inside [Figs. 9(b)-9(d)], each tube forms covalent carbon-carbon bonds with six neighboring tubes. However, in the $(6,0) \mathrm{BC}$ bundle interstitially doped with one $\mathrm{Li}$ atom at a III site [Figs. 9(a) and 10(b)], each tube has only four such carbon-carbon bonds with the neighboring tubes, similar to the case when the bundle is inside doped with three Li atoms [Figs. 8(c) and 10(a)]. Hence, the individual tubes in a bundle doped with one $\mathrm{Li}$ atom at a III site are more distorted than in a bundle doped with one or two $\mathrm{Li}$ atoms at the II sites.

\section{Electronic structure}

The electronic band structures calculated along the $\Gamma-M-K-\Gamma-A-L-H-A$ symmetry directions of the first Brillouin zone and the total DOS for selected hexagonal bundles of Li-doped $(6,0) \mathrm{BC}$ tubes are presented in Fig. 11. The DOS for the corresponding isolated tubes is also presented for comparison. All the bundles of $(6,0) \mathrm{BC}$ tubes doped with $\mathrm{Li}$ atoms are metallic. We have found that increasing the lithium doping both inside the tubes and at the II sites results in a slight upward shifting of the Fermi energy relative to the valence and conduction bands. We have also found that doping inside the tubes with three $\mathrm{Li}$ atoms leads to a slight increase in the total DOS at the Fermi energy compared to that for bundles arranged from clean $(6,0) \mathrm{BC}$ tubes and those doped with one and two Li atoms [see Fig. 11(d)]. The almost flat band found in the valence region just below the Fermi energy for interstitial doping at site III with one $\mathrm{Li}$ atom per cell [Fig. 11(g)] indicates decreased bonding interactions between neighboring tubes in the bundle. While the total DOS structure changes fairly substantially with different doping at the interstitial sites, as shown in Fig. 11(h), the density of states at the Fermi level is seen to remain essentially the same for all of the considered tubes.

\section{Energetics of doping $(6,0) B C$ bundles with Li atoms}

We have analyzed the energetics for different types of doping of $(6,0) \mathrm{BC}$ bundles with $\mathrm{Li}$ atoms. The average binding energy of $\mathrm{N}$ lithium atoms adsorbed in a bundle of $(6,0)$ $\mathrm{BC}$ nanotubes was obtained from the formula ${ }^{33,34}$

$$
\begin{aligned}
E_{\text {bind }}= & {\left[E_{\text {tot }}(\mathrm{BC} \text { bundle })+N E_{\text {tot }}(\mathrm{Li} \text { free })\right.} \\
& \left.-E_{\text {tot }}\left(\mathrm{BC} \text { bundle } \sim \mathrm{Li}_{\mathrm{N}}\right)\right] / \mathrm{N} .
\end{aligned}
$$

In this expression, $E_{\text {tot }}\left(\mathrm{BC}\right.$ bundle $\left.\sim \mathrm{Li}_{\mathrm{N}}\right)$ is the total energy of a fully optimized unit cell of a $(6,0)$ BC bundle doped with $\mathrm{N} \mathrm{Li}$ atoms, $E_{\text {tot }}$ (BC bundle) is the total energy of an optimized unit cell of a clean $(6,0) \mathrm{BC}$ bundle, and $E_{\text {tot }}(\mathrm{Li}$ free) is the energy of one $\mathrm{Li}$ atom in vacuum. This latter quantity was calculated to be $-0.2825 \mathrm{eV} .{ }^{16}$

The intercalation energy ${ }^{32}$ was obtained by subtracting the energy of a unit cell of a $(6,0)$ BC bundle intercalated by $\mathrm{N}$ lithium atoms from the total energy of the unit cell of a clean $(6,0)$ BC bundle,

$$
E_{\mathrm{Li} \text { intercalation }}=E_{\mathrm{tot}}(\mathrm{BC} \text { bundle })-E_{\mathrm{tot}}\left(\mathrm{BC} \text { bundle } \sim \mathrm{Li}_{\mathrm{N}}\right) .
$$

To investigate the possibility of creating high concentrations of $\mathrm{Li}$ within a bundle, we have also calculated the heat of formation, $H_{\mathrm{N}},{ }^{35,36}$ defined as

$$
\begin{aligned}
H_{\mathrm{N}}= & E_{\text {tot }}\left(\mathrm{BC} \text { bundle } \sim \mathrm{Li}_{\mathrm{N}-1}\right)+E_{\text {tot }}(\mathrm{Li} \text { free atom }) \\
& -E_{\text {tot }}\left(\mathrm{BC} \text { bundle } \sim \mathrm{Li}_{\mathrm{N}}\right) .
\end{aligned}
$$

The calculated average binding energy, heat of formation, and intercalation energy of bundles of $(6,0)$ BC tubes inside doped with one to three $\mathrm{Li}$ atoms are presented in Table III. The trends in the intercalation energy produced by doping isolated $(6,0) \mathrm{BC}$ tubes and bundles of $(6,0) \mathrm{BC}$ tubes with Li atoms are shown in Fig. 12. The data in Table III show that interstitial site III is the least stable while interstitial site II is the most energetically preferable site for doping bundles of $(6,0) \mathrm{BC}$ tubes with one $\mathrm{Li}$ atom. Doping inside the tubes in a $(6,0) \mathrm{BC}$ bundle with one Li is slightly less stable than doping at the interstitial II sites. Comparing the total energies of interstitially and internally doped $(6,0) \mathrm{BC}$ bundles, we see that doping with three lithium atoms per unit cell is much more favorable when the bundle is doped at both interstitial II sites and inside the tube than for only internal doping with three $\mathrm{Li}$ atoms.

It is clear from the results in Table III that it would be difficult to achieve high concentrations of lithium by internally doping $(6,0) \mathrm{BC}$ tubes arranged in bundles since the heat of formation becomes negative for more than two dopant atoms per unit cell. The absolute value of the intercalation energy for a bundle of BC tubes inside doped with three $\mathrm{Li}$ atoms is smaller than that for inside doping with two $\mathrm{Li}$ atoms (Table III and Fig. 12). This suggests that the intercalation of the bundle is close to saturation. The average binding energy and the heat of formation for all of the interstitial doping sites that we have considered are positive. The increase in the absolute value of the intercalation energy with increasing concentration of $\mathrm{Li}$ atoms in interstitially doped $(6,0) \mathrm{BC}$ bundles suggests that high concentrations of lithium can be achieved by combining interstitial doping at II sites with inside doping of the tubes (see Table III and Fig. 12).

\section{SUMMARY}

In this paper, we have reported results of detailed $a b$ initio calculations of the atomic structure and electronic properties of bundles arranged from small-diameter clean BC tubes and the same tubes doped with $\mathrm{Li}$ and $\mathrm{Cu}$ atoms.

We have found that bundles of small-diameter clean BC tubes, and those doped internally with $\mathrm{Li}$ or $\mathrm{Cu}$ atoms, are 

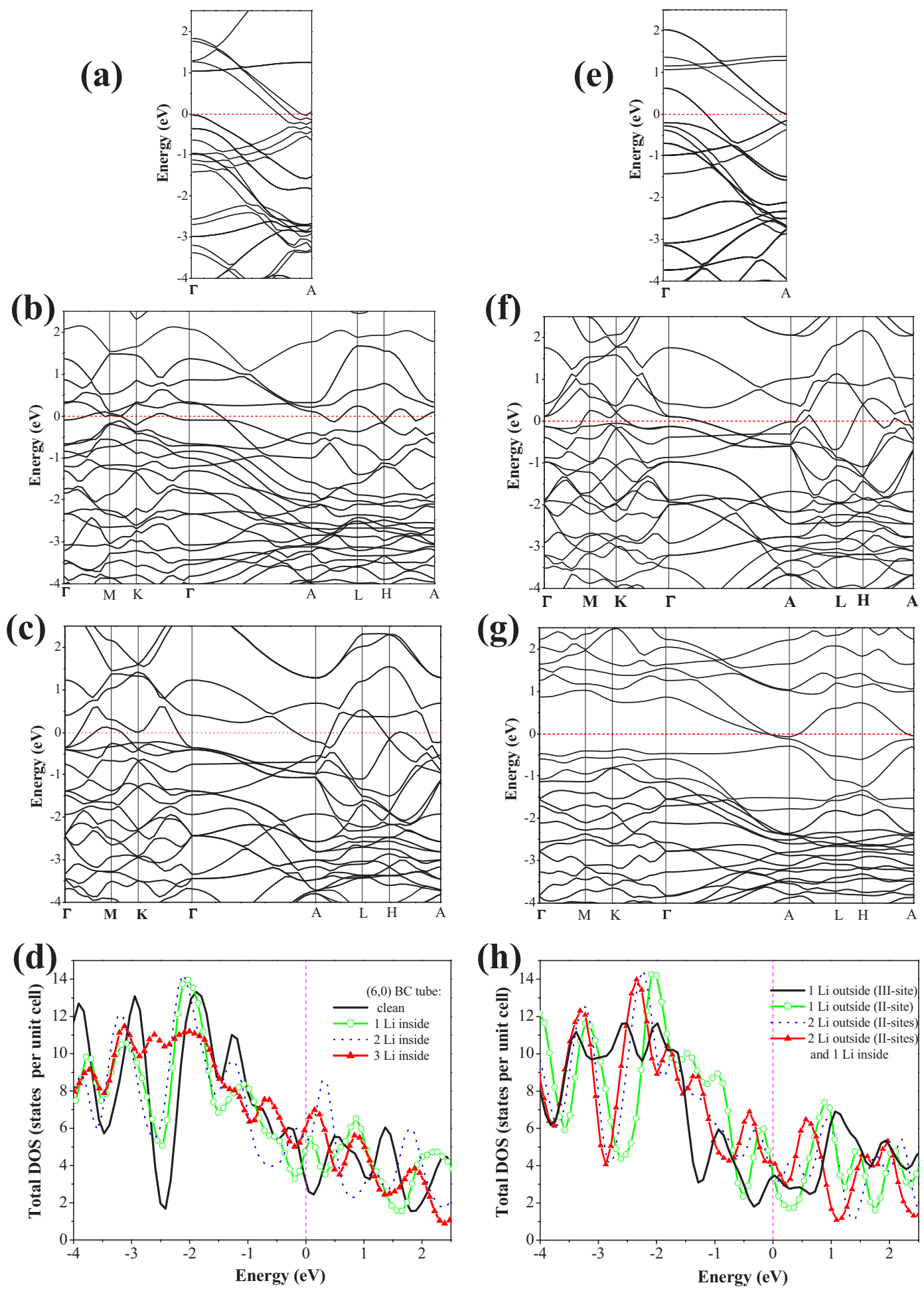

FIG. 11. (Color online) The electronic band structures calculated along the $\Gamma$ - $A$ direction for isolated $(6,0)$ BC tubes doped inside with (a) three lithium atoms and (e) one lithium atom. The electronic band structures calculated along the $\Gamma-M-K-\Gamma-A-L-H-A$ symmetry directions of the first Brillouin zone for bundles of $(6,0) \mathrm{BC}$ tubes doped (b) internally with three Li atoms per cell, (c) interstitially with three atoms of Li per unit cell, (f) internally with one Li atom per cell, and (g) interstitially at site III with one Li atom per cell. Total DOS for (6,0) BC tubes doped with one to three lithium atoms per unit cell internally (d) and interstitially (h).

more energetically stable than the corresponding isolated tubes. The atomic structure of clean $\mathrm{BC}$ bundles has been found to depend on the symmetry of the individual $\mathrm{BC}$ tubes in the bundle. Clean $(6,0)$ tubes were seen to form symmetric hexagonal bundles in which each tube is covalently bonded to six neighboring tubes via the formation of strong carboncarbon bonds. By contrast, each clean $(4,4) \mathrm{BC}$ tube in a hexagonal bundle interacts with only four neighboring tubes 


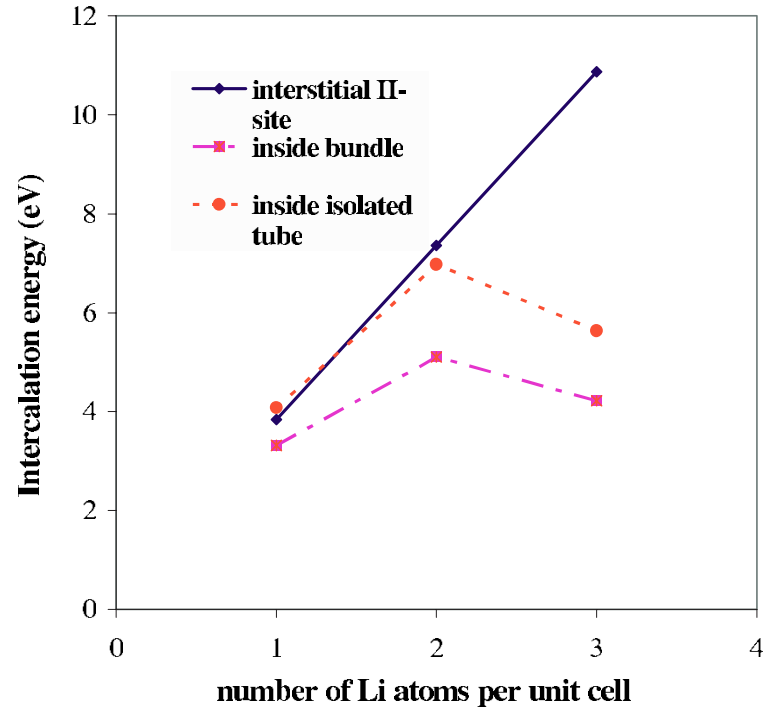

FIG. 12. (Color online) Intercalation energy for different concentrations of $\mathrm{Li}$ atoms per unit cell for isolated $(6,0) \mathrm{BC}$ tubes and bundles of $(6,0) \mathrm{BC}$ tubes.

via intertubular covalent carbon-boron and carbon-carbon bonds. The resultant geometries represent clathratelike structures with strong resemblance to layered three-dimensional $\mathrm{BC}$ structures. Such structural deformations of narrow clean $\mathrm{BC}$ tubes within bundles have not been reported previously. We have also shown that the channel cavities within these structures can be used as moulds to form stable metal-doped tubular bundles.

Interactions between neighboring narrow $\mathrm{BC}$ tubes doped with $\mathrm{Li}$ and $\mathrm{Cu}$ also lead to the formation of covalent bonding between the tubes. This significantly affects the atomic and electronic structure of the bundles compared to the corresponding isolated tubes. Bundles formed from $(4,4) \mathrm{BC}$ tubes doped internally with $\mathrm{Cu}$ atoms show structural resemblance to layered three-dimensional BC structures intercalated with $\mathrm{Cu}$. The cross sections of bundles formed from $(6,0) \mathrm{BC}$ tubes doped internally with three lithium atoms per unit cell, and those interstitially doped with one $\mathrm{Li}$ at the III site, resemble the layered structure of $\mathrm{LiBC}$.
Analysis of the electronic structure of bundles doped with lithium has revealed a mainly ionic character for the interactions between the $\mathrm{Li}$ atoms and the boron-carbon tubular shells. We have found that for in-tube doping of the $\mathrm{BC}(6,0)$ bundles with one and two $\mathrm{Li}$ atoms, charge is transferred from the dopant atoms to the shell of the tubes. For in-tube doping with three Li atoms, however, the dopant atoms retain their charge. While this latter effect reduces the repulsive interaction between the $\mathrm{Li}$ atoms inside each tube, internally doping $\mathrm{BC}(6,0)$ bundles with more than two lithium atoms per unit cell was found to be energetically unfavorable. By contrast, doping with two lithium atoms inside each cell, and one $\mathrm{Li}$ at a symmetrical interstitial site, was determined to be energetically favorable. This latter result suggests that doping bundles of $\mathrm{BC}(6,0)$ tubes both interstitially and internally with lithium may form the basis for a lithium storage system with significant potential applications.

Analysis of the charge density of the Cu-doped BC $(4,4)$ bundles has shown a predominantly covalent bonding character between the $d$ orbitals of the $\mathrm{Cu}$ atoms and the carbon atoms on the tubular shell. As a result of interactions between adjacent tubes in a bundle, $(4,4) \mathrm{BC}$ tubes doped with one and two internal $\mathrm{Cu}$ atoms are deformed. Doping each $(4,4) \mathrm{BC}$ tube internally with two $\mathrm{Cu}$ atoms leads to an approximately $15 \%$ increase in the total density of states near the Fermi level compared to $(4,4) \mathrm{BC}$ tubes doped with just one $\mathrm{Cu}$ atom per unit cell. Similar effects have not been observed for the $\mathrm{BC}(6,0)$ bundles doped with Li. These results may be important in the current dispute regarding superconductivity in the layered compounds. ${ }^{37,38}$ In general, the presented results demonstrate that nanotubular structures composed of bundles of narrow $\mathrm{BC}$ tubes are viable and possess interesting structural and electronic properties. Complete understanding of these properties is a necessary first step in determining the possible potential applications of these intriguing nanotubular materials.

\section{ACKNOWLEDGMENTS}

One of us (O.P.) would like to thank the University of Newcastle for financial support. We would also like to thank the APAC Supercomputing Facility for processing time and the Space Physics Group of the University of Newcastle for access to their SUN ULTRA-HPC450 computer.

\footnotetext{
*Corresponding author. FAX: 61-2-49-216907; marian.radny@newcastle.edu.au

${ }^{1}$ H. Terrones, M. Terrones, F. Lopez-Urías, J. Rodríguez-Manzo, and A. Mackay, Philos. Trans. R. Soc. London, Ser. A 362, 2039 (2004).

${ }^{2}$ R. Tenne and A. Rao, Philos. Trans. R. Soc. London, Ser. A 362, 2039 (2004).

${ }^{3}$ M. Remskar, Adv. Mater. (Weinheim, Ger.) 16, 1497 (2004).

${ }^{4}$ R. Tenne, L. Margulis, M. Genut, and G. Hodges, Nature (London) 360, 444 (1992).

${ }^{5}$ N. Chopra, R. Luyken, K. Cherrey, V. Crespi, M. Cohen, S. Louie, and A. Zettl, Science 269, 966 (1995).

${ }^{6} \mathrm{R}$. Tenne, Cluster Assembled Materials (Transtec, ZurichUetikon, 1996), Vol. 232, p. 275.

${ }^{7}$ A. Ivanovskii, Phys. Solid State 45, 1829 (2003).

${ }^{8}$ E. Montevecchi and J. O. Indekeu, Phys. Rev. B 62, 14359 (2000).

${ }^{9}$ A. Quandt, A. Y. Liu, and I. Boustani, Phys. Rev. B 64, 125422 (2001).

${ }^{10}$ V. Ivanovskaya, A. Enjashin, A. Sofronov, Y. Makurin, N. Medvedeva, and A. Ivanovskii, J. Mol. Struct.: THEOCHEM 625, 9 (2003).

${ }^{11}$ A. Ivanovskii and N. Medvedeva, Russ. J. Inorg. Chem. 45, 1234 (2000).
} 
${ }^{12}$ P. Zhang and V. H. Crespi, Phys. Rev. Lett. 89, 056403 (2002).

${ }^{13}$ S. Guerini and P. Piquini, Microelectron. J. 34, 495 (2003).

${ }^{14}$ I. Shein, V. Ivanovskaya, N. Medvedeva, and A. Ivanovskii, JETP Lett. 76, 189 (2002).

${ }^{15}$ O. Ponomarenko, M. W. Radny, P. V. Smith, and G. Seifert, Phys. Rev. B 67, 125401 (2003).

${ }^{16}$ O. Ponomarenko, M. W. Radny, and P. V. Smith, Phys. Rev. B 74, 125421 (2006).

${ }^{17}$ H. Rosner, A. Kitaigorodsky, and W. E. Pickett, Phys. Rev. Lett. 88, 127001 (2002).

${ }^{18}$ M. J. Mehl, D. A. Papaconstantopoulos, and D. J. Singh, Phys. Rev. B 64, 140509(R) (2001).

${ }^{19}$ Z. Tang, N. Wang, X. Zhang, J. Wang, C. Chan, and P. Sheng, New J. Phys. 5, 146 (2003).

${ }^{20}$ M. Remskar, A. Mrzel, Z. Skraba, A. Jesih, M. Ceh, J. Demsar, P. Stadelmann, F. Levy, and D. Mihailovic, Science 292, 479 (2001)

${ }^{21}$ V. Pokropivny, Physica C 351, 71 (2001).

${ }^{22}$ B. Gao, C. Bower, J. Lorentzen, L. Fleming, A. Kleinhammes, X. Tang, L. McNeil, Y. Wu, and O. Zhou, Chem. Phys. Lett. 327, 69 (2000).

${ }^{23}$ Z. Zhou, X. Gao, J. Yan, D. Song, and M. Morinaga, Carbon 42, 2677 (2004).

${ }^{24}$ J. P. Perdew, J. A. Chevary, S. H. Vosko, K. A. Jackson, M. R. Pederson, D. J. Singh, and C. Fiolhai, Phys. Rev. B 46, 6671 (1992).

${ }^{25}$ G. Kresse and J. Hafner, J. Phys.: Condens. Matter 6, 8245
(1994).

${ }^{26}$ G. Kresse and J. Furthmuller, Phys. Rev. B 54, 11169 (1996).

${ }^{27}$ G. Kresse and J. Furthmuller, Vienna ab initio simulation package VASP, the guide (http://cms.mpi.univie.ac.at), 2001.

${ }^{28}$ H. Monkhorst and J. Pack, Phys. Rev. B 13, 5188 (1976).

${ }^{29}$ M. Bernasconi, S. Gaito, and G. Benedek, Phys. Rev. B 61, 12689 (2000).

${ }^{30}$ V. Timoshevskii, D. Connetable, and X. Blase, Appl. Phys. Lett. 80, 1385 (2002).

${ }^{31}$ D. Connetable, V. Timoshevskii, B. Masenelli, J. Beille, J. Marcus, B. Barbara, A. M. Saitta, G. M. Rignanese, P. Melinon, S. Yamanaka, and X. Blase, Phys. Rev. Lett. 91, 247001 (2003).

${ }^{32}$ J. Zhao, A. Buldum, J. Han, and J. Lu, Phys. Rev. Lett. 85, 1706 (2000).

${ }^{33}$ Y. Yagi, T. M. Briere, M. H. F. Sluiter, V. Kumar, A. A. Farajian, and Y. Kawazoe, Phys. Rev. B 69, 075414 (2004).

${ }^{34}$ J. Yang, H. J. Liu, and C. T. Chan, Phys. Rev. B 64, 085420 (2001).

${ }^{35}$ Y. Miyamoto, A. Rubio, X. Blase, M. L. Cohen, and S. G. Louie, Phys. Rev. Lett. 74, 2993 (1995).

${ }^{36}$ A. Rubio, Y. Miyamoto, X. Blase, M. L. Cohen, and S. G. Louie, Phys. Rev. B 53, 4023 (1996).

${ }^{37}$ A. Fogg, J. Meldrum, G. Darling, J. Claridge, and M. Rosseinsky, J. Am. Chem. Soc. 128, 10043 (2006).

${ }^{38}$ S. Lebègue, B. Arnaud, and M. Alouani, Comput. Mater. Sci. 37, 220 (2006) 